Trans. AIME (1949) 180, 92. Metals Tech. (Sept. 1948) TP 2441.

25. J. P. Sheehan, C. H. Julian and A. R. Troiano: The Transformation Characteristics of Ten Selected Nickel Steels. Trans. ASM, (1948)
Preprint No. 6.

26. F. Bollenrath and W. Bungardt: Einige Beobachtungen im System Aluminum-Kupfer an Legierungen mit 8 bis $16 \%$ Al. Ztsch. Metallk. (1943) 35, 153.
27. P. L. Grusin and G. Kurdjumov: Transformations in the Eutectoidal Alloys of Cu-Al. VI Specific Heat Measurements for the $\beta^{\prime} \rightarrow \beta_{1}$ Transformation. Jnl. Tech. Phys. (U.S.S.R.) (1940) 10, 1680.

\title{
Compression Textures of Copper and Its Binary Alpha Solid Solution Alloys*
}

WALTER R. HIBBARD, JR., $\dagger$ and DELMAR E. TROUT, II, $\ddagger$ Junior Members AIME

Previous investigations have shown that the cold rolling textures ${ }^{1,2}$ and the drawn wire textures ${ }^{3}$ of copper change their secondary components after the addition of about 1 pct aluminum and 5 pct zinc, but do not change after the addition of as much as 30 pct nickel. However, few data are available on compression textures. Barrett ${ }^{4}$ reports from unpublished work with E. L. Layland that compression rolled copper develops a texture which is predominately $\{110\}$ in the compression plane with a secondary spread to $\{113\}$ and weaker spread to $\{100\}$ as shown in Fig 1. However, 70-30 alpha brass similarly treated develops a texture again predominately $\{110\}$ in the compression plane and with a weak secondary spread to $\{113\}$ but with moderate \{111\} secondary intensities illustrated in Fig 2.

\section{Experimental Procedure}

Specimens of the compositions shown in Table 1 remaining from a previous investigation ${ }^{3}$ were annealed to a grain size of $0.090 \mathrm{~mm}$ average diam and machined to cylinders 0.20 in. diam and $0.20 \mathrm{in}$. high. Cylinders were compressed 90 pct reduction in height between lubricated steel blocks in a tensile machine. Glancing $\mathrm{X}$ ray photograms using copper $\mathbf{K}$-alpha radiation were taken at an angle of $\theta$ degrees to the compression surface. (111), (002) and (220) rings were analyzed to define the textures shown in Table 1.

The results are in agreement with Barrett $^{4}$ as to types of textures and are essentially in agreement with previous work $^{1,2,3}$ as to the effects of composition. In the wire study ${ }^{3}$ it was reported that the 4.99 pct zinc alloy had a brasstype texture, while the data in Table 1 indicate a copper-type texture for compression. The wire specimen of the 4.99 pct zinc alloy was re-examined by $\mathrm{X}$ rays and it was established that the [100] component still exists in the wire axis. Therefore, Table 2 of Ref. 3 is in

error and should indicate a double [111], [100] copper-type texture for this alloy. This correction results in complete consistency with regard to compositional effects, namely that copper and its alloys containing up to approximately 1 pct aluminum, 5 pct zinc and at least 30 pct nickel§ develop a copper-type texture and more concentrated copper-aluminum and copper-zinc solid solution alloys will form a brass-type texture.

\section{Summary}

Compression textures developed in copper and its alpha solid solution alloys of aluminum, nickel and zinc are essentially the same types as those re-

Table 1 ... Composition and Texture

\begin{tabular}{|c|c|c|c|c|c|c|c|}
\hline \multirow{2}{*}{ Material } & \multicolumn{2}{|c|}{ Composition } & \multicolumn{5}{|c|}{ Texture of Compression Plane } \\
\hline & Wt. Pet & At. Pct & $\{110\}$ & $\{111\}$ & $\{100\}$ & $\{113\}$ & Fig \\
\hline 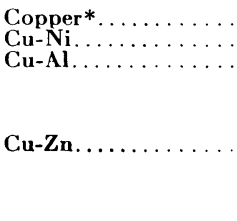 & $\begin{array}{r}30.70 \\
0.94 \\
3.69 \\
7.76 \\
4.99 \\
10.16 \\
12.42 \\
29.22\end{array}$ & $\begin{array}{r}32.44 \\
2.16 \\
8.28 \\
16.58 \\
4.83 \\
9.90 \\
12.12 \\
30.00\end{array}$ & $\begin{array}{l}\mathbf{S} \\
\mathbf{S} \\
\mathbf{S} \\
\mathbf{S} \\
\mathbf{S} \\
\mathbf{S} \\
\mathbf{S} \\
\mathbf{S}\end{array}$ & $\begin{array}{l}\mathbf{W} \\
\mathbf{M} \\
\mathbf{M} \\
\mathbf{M} \\
\mathbf{M} \\
\mathbf{M}\end{array}$ & $\begin{array}{l}\mathbf{W} \\
\mathbf{W} \\
\mathbf{W}\end{array}$ & $\begin{array}{l}\mathbf{M} \\
\mathbf{M} \\
\mathbf{M} \\
\mathbf{W} \\
\mathbf{W} \\
\mathbf{M} \\
\mathbf{W} \\
\mathbf{W} \\
\mathbf{W}\end{array}$ & $\begin{array}{c}1 \\
1 \\
\text { Transition } \\
\text { between 1 and } 2 \\
2 \\
2 \\
1 \\
2 \\
2 \\
2\end{array}$ \\
\hline
\end{tabular}

* Phosphorous deoxidized electrolytic copper

ported by Barrett ${ }^{4}$ with compositional effects occurring at approximately the same percent additions as previously reported for rolled sheet ${ }^{1,2}$ and drawn wire. $^{3}$

$\S$ Higher nickel alloys were not investigated.

Technical Note No. 18E. Manuscript received April 25, 1949.

* Some of the data included in this paper are from a report presented to the Faculty of the School of Engineering, Yale University, by Delmar E. Trout, II, in candidacy for the Degree of Master of Engineering, May 1948. $\dagger$ Assistant Professor of Metallurgy, Yale University, New Haven, Conn. $\ddagger$ Scovill Manufacturing Co., Waterbury, Conn.

1 References are at the end of the note.

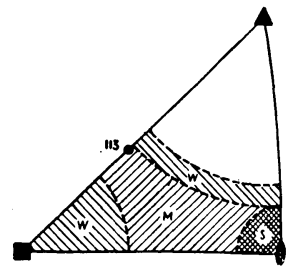

FIG 1-Orientations in copper compressed 97 pet by compression rolling (Barrett).

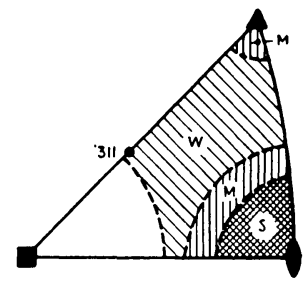

FIG 2-Orientations in $70-30$ brass compressed 97 pct by compression rolling (Barrett).

\section{Acknowledgment}

The Scovill Manufacturing Co., Waterbury, Conn., furnished the copper and brass alloys, performed certain chemical analyses and supplied laboratory facilities where needed.

\section{References}

1. Brick, Martin and Angier: Trans. A.S.M. (1943) 31, 675 .

2. Dahl and Pawlek: Ztsch. Metall. (1936) 28, 266.

3. Hibbard and Yen: Trans. AIME 175. 126. Metals Tech., Feb. 1948, TP 2334.

4. Barrett: Structure of Metals, McGraw-Hill (1942), 386. 